\title{
Household environmental factors and children's respiratory health: comparison of two cross-sectional studies over 25 years in Wuhan, China
}

\author{
Xin Meng ${ }^{1,2 \#}$, Suzhen Cao ${ }^{1 \#}$, Sai Li ${ }^{1}$, Meilin Yan $^{2}$, Qian Guo ${ }^{1}$, Jicheng Gong ${ }^{2}$, Qin Liu ${ }^{3}$, \\ Junfeng Jim Zhang ${ }^{4,5,6}$, Xiaoli Duan ${ }^{1}$
}

${ }^{1}$ School of Energy and Environmental Engineering, Beijing Key Laboratory of Resource-oriented Treatment of Industrial Pollutants, University of Science and Technology Beijing, Beijing, China; ${ }^{2}$ Beijing Innovation Center for Engineering Science and Advanced Technology, State Key Joint Laboratory for Environmental Simulation and Pollution Control, College of Environmental Sciences and Engineering, And Center for Environment and Health, Peking University, Beijing, China; ${ }^{3}$ School of Public Health and Management, Chongqing Medical University, Chongqing, China; ${ }^{4}$ Global Health Research Center, Duke Kunshan University, Kunshan, China; ${ }^{5}$ Nicholas School of the Environment and Duke Global Health Institute, Duke University, Durham, USA; ${ }^{6}$ Guangzhou Institute of Respiratory Health, The First Affiliated Hospital of Guangzhou Medical University, Guangzhou, China

Contributions: (I) Conception and design: JJ Zhang, J Gong, X Duan, S Cao, Q Liu; (II) Administrative support: JJ Zhang, J Gong, X Duan, S Cao, Q Liu; (III) Provision of study materials or patients: S Cao, S Li, Q Guo; (IV) Collection and assembly of data: S Li, Q Guo; (V) Data analysis and interpretation: X Meng, S Cao, M Yan; (VI) Manuscript writing: All authors; (VII) Final approval of manuscript: All authors.

\#These authors contributed equally to this work.

Correspondence to: Xiaoli Duan. University of Science and Technology Beijing, Beijing, China. Email: jasmine@ustb.edu.cn; Jicheng Gong. Peking University, Beijing, China. Email: jicheng.gong@pku.edu.cn.

Background: Over the recent decades, residential lifestyle and household environment have changed substantially with rapid development of industrialization and urbanization in China. Whether the prevalence of respiratory diseases changed is still lack of evidence. The objective of this study is to assess potential changes in children's respiratory disease prevalence and associated household environmental factors in Wuhan over a 25 -year time interval.

Methods: Two cross-sectional studies in the Period 1 (1993 to 1996) and Period 2 (2017 to 2018) were compared in this research. Elementary school children in period $1(\mathrm{~N}=2,517)$ and in period $2(\mathrm{~N}=3,152)$ were recruited in Wuhan, China. The respiratory health condition, home environmental factors, and family socioeconomic status of each subject were acquired through questionnaire survey using the same protocols in both periods. We used the Chi-square test to analyze the difference of household environmental factors (focused on three indoor air quality determinants) and children's respiratory health condition between two periods. Logistic regression models were used to assess the impacts of household environmental determinants on children's respiratory diseases and symptoms between the two studies, by adjusting a set of covariates.

Results: The three indoor air quality determinants have reduced substantially in prevalence from period 1 to period 2: environment tobacco smoke (ETS) from $86.6 \%$ to $45.9 \%$, household coal use from $47.6 \%$ to $4.9 \%$, and kitchen smoke from $58.9 \%$ to $7.3 \%$. The prevalence of certain respiratory symptoms in children significantly decreased, such as cough with colds $(51.1 \%$ to $41.6 \%)$ and phlegm with colds $(22.3 \%$ to $17.7 \%$ ). The prevalence of asthma was $2.5 \%$ and $2.4 \%$ and that of bronchitis was $27.1 \%$ and $29.8 \%$ in both periods. Coal use was a risk factor for asthma in period 1 (OR $=2.34,95 \% \mathrm{CI}: 1.30-4.23)$, while it was not significantly associated with prevalence of asthma in period 2 (OR =0.60, 95\% CI: 0.08-4.51).

Conclusions: Household indoor air quality determinants and respiratory health condition of children in Wuhan has been improved over the last 25 years. At present, kitchen smoke is an important factor affecting the prevalence of wheeze whatever child has a cold or not and reducing exposure to ETS could be beneficial to protect children to be less likely to develop bronchitis. 
Keywords: Household indoor environment; children; respiratory disease; symptoms

Submitted Jun 10, 2020. Accepted for publication Apr 05, 2021.

doi: $10.21037 /$ jtd-20-2170

View this article at: https://dx.doi.org/10.21037/jtd-20-2170

\section{Introduction}

Respiratory diseases have been a major health burden in children. Lower respiratory tract infections are one of the leading causes of death worldwide in children, especially in developing countries (1-3). A study of several respiratory diseases in one of the largest children's teaching hospitals in China between 2009 and 2018 has reported that the top four most prevalent respiratory diseases were bronchitis with a prevalence of $27.6 \%$, pneumonia (18.5\%), pneumonia affecting other systems (18.4\%), and asthma and status asthmaticus (10.7\%). These four diseases accounted for $75.2 \%$ of all records of respiratory disease diagnoses (4). Children with respiratory diseases were more likely to be absent from school, suffer from sleeping disruptions and mental health disorders $(5,6)$. Respiratory infection in early childhood may develop respiratory diseases in adult life, for instance, children with moderate to severe asthma tend to persist to adulthood (7).

Air pollution has been one of the recognized risk factors for respiratory health $(8,9)$. Air pollutants originated from indoor sources, such as coal burning, environmental tobacco smoke (ETS), and kitchen smoke, often contribute to the total exposure more than pollutants from outdoors, especially in children who spent most of their time indoors (10-12). For example, children's acute lower-respiratory-tract infections attributable to indoor air pollution accounted for $4.6 \%$ of all deaths and $3.1 \%$ of disability-adjusted life years in Europe (13). A review concluded that environmental tobacco smoke exposure is a major risk factor for acute and chronic respiratory illness and reduced lung function (14). Coal use for household cooking and space heating has been recognized to cause substantial respiratory diseases due to the incomplete combustion and poor ventilation (15). Epidemiologic studies have shown that exposure to kitchen smoke is associated with respiratory health $(16,17)$. These indoor air pollution sources or determinants may have changed substantially in Chinese cities over the last decades. Such changes may have significant impact on children's respiratory health conditions. On the other hand, socioeconomic, lifestyle, and parental health conditions may have also changed substantially with the rapid economic development and urbanization. These factors may affect children's respiratory health as well $(18,19)$.

Although urban living is associated with having a better standard of living in developing countries and has been generally considered as a beneficial factor for children's health. However, a study in Malaysia found that children living in households or studying in schools in urban areas are more likely to suffer from respiratory illnesses compared with children living in homes or studying in schools in rural areas (20). Adverse factors for urban living include poor air quality especially in Chinese cities as Wuhan located (21). Moreover, it remains uncertain that whether the prevalence of respiratory symptoms and diseases in Chinese children has changed over the past decades. Remarkably, China with its rapid economic and social development offers a natural contrast scenario to see how children's respiratory symptoms and diseases changes as society develops and whether the household environmental risk factors still play the same roles in their respiratory health.

This study was designed to leverage a previous study carried out in four Chinese cities in 1993 to 1996, which was the first study on the health effects of air pollution on Chinese children's respiratory health (22). In order to examine the potential changes in respiratory disease prevalence in relation to changes in household air quality determinants, we conducted a follow-up cross-sectional survey in the same four Chinese cities in 2017 to 2018 using the same study protocols. In this study, we took Wuhan, located in central China as an example, to compare health outcomes and household exposure factors as well as socioeconomic and parental history of respiratory disease between period 1 (1993 to 1996) and period 2 (2017 to 2018).

We present the following article in accordance with the STROBE reporting checklist (available at https://dx.doi. org/10.21037/jtd-20-2170).

\section{Methods}

\section{Study city and population}

Wuhan is the capital city of Hubei province located in central China. It has a subtropical monsoon climate as located in the transitional zone of China's geographical 
characteristics. Wuhan's permanent resident population was 11.2 million in 2018 (23). As a representative of the major megalopolis in central China, Wuhan has developed rapidly in social and economic as GDP grew nearly four times in the last decade (2008 to 2018) $(24,25)$.

A total of 2,517 children (male: $1,253,49.8 \%$; female: $1,264,59.2 \%$ ) participated in the period 1 study. There were 1,923 and 594 students chosen from an urban and a then suburban elementary school, respectively. Since the two schools which were selected 25 years ago did not exist now, six elementary schools located in the same districts where the period 1 schools located were chosen in the period 2 study. A total of 3,152 children were recruited from the six primary schools with a distribution of male 1,798 (57.0\%) and female 1,354 (43.0\%) child participants. Among them, one school in suburban area covered 1,167 children, five schools in urban area covered 1,985 children because of the small enrolment in each school. In every school, stratified sampling was conducted by each grade and children had an age of $9.81 \pm 1.60$ and $8.88 \pm 1.38$ in period 1 and period 2, respectively. This study was approved by the Committee on Ethics of Biomedicine Research, Duke Kunshan University, Jiangsu (No. FWA00021580). Parents gave written consent for the participation of themselves and their children in the study. The study was conducted in accordance with the Declaration of Helsinki (as revised in 2013).

\section{Questionnaire survey}

All the parents were asked to fill in a questionnaire concerning exposure to potential risk factors that might influence children's respiratory health and the presence of symptoms of respiratory disease. The questionnaire of period 1 was adapted from American Thoracic Society Epidemiology Standardization Project (ATS-DLD-78-C) (26), which was composed of three parts concerning general family information including family member and lifestyle and household indoor environment, child's respiratory health and their parents information such as educational levels and occupations. Except for the same questions as in period 1 , some additional questions were added in period 2 according to the characteristics of the current social lifestyle.

The original values of the questionnaire responses were double inputted. In order to compare the influence of household environmental factors to children's respiratory health between the two study periods, the questionnaire responses of identical questions in two periods were combined into a database according to a standardized code book and file structure. Since socioeconomic status was typically evaluated by parents' education level and occupation, we classified parents' education into low (high school or below) and high (technical college, university or above). Parental occupation was classified into 'white collar' and 'blue collar' basically according to the labor types and risk of occupational exposure (27). The former referred to businessman, educational or medical staff, civil servant, and military personnel, while the latter referred to farmer and factory worker in the production of chemicals, fertilizers, and paints. Parents' history of respiratory diseases, such as 'Has a doctor ever diagnosed asthma' and 'Has a doctor ever diagnosed bronchitis' was also investigated.

\section{Definitions of bousebold risk factors and bealth outcomes}

This study concerned about the common sources of household air hazards and typical childhood respiratory diseases. Based on the information both investigated in two questionnaire surveys, we focused on the health effects of three household environmental factors on children's respiratory health, namely, indoor coal use, ETS, and kitchen smoke. Therefore, the data were preprocessed to be consistent and we assessed household environmental determinants using the questions in Table 1, such as kitchen smoke was determined by question 'What is the ventilation for cooking in the kitchen?' and answering other than 'open window' and 'nothing' is determined to be the presence of kitchen smoke. Respiratory symptoms and diseases are determined by the questions showed in Table 2. Respiratory symptoms were self-reported by children's guardian and the history of respiratory diseases should ever be diagnosed by doctor.

\section{Statistical analysis}

The continuous variables were described as mean $\pm \mathrm{SD}$, while the categorical variables were showed as numbers and proportions. To assess the changes of household environmental factors and children's respiratory health conditions from period 1 to period 2, we calculated the percentage of the home environmental characteristics and the prevalence of children's respiratory symptoms and diseases. We carried out chi-square tests to examine differences between the two periods. Logistic regression models were used for exploring the association of ETS, coal use and kitchen smoke on children's respiratory symptoms 
Table 1 Questions and definitions of household environmental determinants

\begin{tabular}{lll}
\hline $\begin{array}{l}\text { Household environmental } \\
\text { determinants }\end{array}$ & Questions & Classification criteria \\
\hline Coal use & $\begin{array}{l}\text { Whether coal is the main fuel of heating your home? (yes/no) } \\
\text { Whether coal is your main fuel for cooking? (yes/no) }\end{array}$ & $\begin{array}{l}\text { Either answering yes to the two questions is } \\
\text { determined to be the presence of coal use }\end{array}$ \\
ETS & $\begin{array}{ll}\text { Has father ever smoked? (yes/no) } \\
\text { Has mother ever smoked? (yes/no) }\end{array}$ & $\begin{array}{l}\text { Either parent answering yes is determined to be } \\
\text { the presence of ETS }\end{array}$ \\
Kitchen smoke & $\begin{array}{l}\text { What is the ventilation for cooking in the kitchen? (hood/fan// } \\
\text { chimney/open window/nothing) }\end{array}$ & $\begin{array}{l}\text { Answering other than 'open window' and } \\
\text { 'nothing' is determined to be the presence of } \\
\text { kitchen smoke }\end{array}$ \\
\hline
\end{tabular}

Table 2 Questions and definitions of respiratory symptoms and diseases in children

\begin{tabular}{ll}
\hline Respiratory health condition & Question \\
\hline Symptoms & Has this child ever coughed when having a cold? (yes/no) \\
Cough with colds & Has this child ever coughed when not having a cold? (yes/no) \\
Cough without colds & Has this child ever has brought up phlegm or mucus from the chest when having a cold? (yes/no) \\
$\begin{array}{l}\text { Phlegm with colds } \\
\text { Phlegm without colds }\end{array}$ & Has this child ever has brought up phlegm or mucus from the chest when not having a cold? (yes/no) \\
Wheeze with colds & Has this child's chest ever sounded wheezy or whistling when having a cold? (yes/no) \\
Wheeze without colds & Has this child's chest ever sounded wheezy or whistling when not having a cold? (yes/no) \\
Diseases & Has a doctor ever diagnosed asthma in this child? (yes/no) \\
Asthma & Has a doctor ever diagnosed bronchitis in this child? (yes/no) \\
Bronchitis &
\end{tabular}

and disease and also used to compare whether the role of the risk factors in two periods have changed, by adjusting the confounders such as residential area, gender, age, parental occupation, parental education, breast-feeding, sleeping in own room, sleeping in own bed, parental asthma, parental bronchitis. When assessing the health effect of ETS, coal use and kitchen smoke were also adjusted for in the ETS model. In the same way, the coal use model was adjusted for ETS and kitchen smoke, and the kitchen smoke model was adjusted for ETS and coal use. The data were analyzed using the statistical software SPSS 26.0 version. All statistical tests were two tailed, and statistical significance was declared when a $\mathrm{P}$ value was $<0.05$.

\section{Results}

The information of study subjects, family conditions and parental characteristics are shown in Table 3. The proportion of parents as blue-collar workers decreased after 25 years, although this still accounted for a significant proportion among occupation types in period 2 (48.1\% for father and $42.1 \%$ for mother). There was a slight improvement in parental education level in period 2. The prevalence of paternal asthma and maternal asthma showed a decrease from period 1 to period 2, for example, $1.4 \%$ of mothers suffered from asthma in period 1 versus $0.5 \%$ in period 2 . Also, the prevalence of parental bronchitis decreased from period 1 to period 2, particularly for paternal bronchitis (14.9\% versus $6.1 \%)$. The proportion of exposure to coal use, ETS and kitchen smoke have all markedly decreased from period 1 to period $2(\mathrm{P}<0.001)$ (Table 3). The proportion of exposure to ETS fell by approximately half from $86.5 \%$ to $45.9 \%$. Coal smoke exposure and kitchen smoke exposure have both reduced even more, from more than $40 \%$ to less than $10 \%$.

The respiratory health conditions of children are 
Table 3 Characteristics of subjects, parental and household environmental factors in the two study periods

\begin{tabular}{|c|c|c|c|}
\hline Characteristics & Period 1 & Period 2 & $P$ for period difference \\
\hline Age (year, mean \pm SD) & $9.81 \pm 1.60$ & $8.88 \pm 1.38$ & $<0.001$ \\
\hline District, n (\%) & & & $<0.001$ \\
\hline Urban & $1,923(76.4)$ & $1,985(63.0)$ & \\
\hline Gender, n (\%) & & & $<0.001$ \\
\hline Male & $1,253(49.8)$ & $1,798(57.0)$ & \\
\hline Female & $1,264(50.2)$ & $1,354(43.0)$ & \\
\hline Environmental tobacco smoke (ETS), n (\%) & $2,083(86.6)$ & $1,382(45.9)$ & $<0.001$ \\
\hline Sleep in own room, $n(\%)$ & $713(28.3)$ & $1,573(51.2)$ & $<0.001$ \\
\hline Sleep in own bed, n (\%) & $1,599(63.6)$ & $1,938(63.4)$ & 0.916 \\
\hline Breast feeding, n (\%) & $1,707(67.8)$ & $2,402(82.7)$ & $<0.001$ \\
\hline Father occupation ${ }^{1}, \mathrm{n}(\%)$ & & & $<0.001$ \\
\hline Blue collar $^{2}$ & $1,490(59.8)$ & $1,439(48.1)$ & \\
\hline White collar ${ }^{3}$ & $964(38.7)$ & $1,143(38.2)$ & \\
\hline Mother occupation ${ }^{1}, \mathrm{n}(\%)$ & & & $<0.001$ \\
\hline Blue collar ${ }^{2}$ & $1,470(59.1)$ & $1,195(42.1)$ & \\
\hline Less than high school & $2,331(93.7)$ & $2,364(79.0)$ & \\
\hline University and above & $156(6.3)$ & $628(21.0)$ & \\
\hline \multicolumn{4}{|l|}{ Father diseases, $\mathrm{n}(\%)$} \\
\hline Asthma & $38(1.5)$ & $23(0.8)$ & 0.010 \\
\hline Bronchitis & 373 (14.9) & $179(6.1)$ & $<0.001$ \\
\hline \multicolumn{4}{|l|}{ Mother diseases, n (\%) } \\
\hline Asthma & $34(1.4)$ & $15(0.5)$ & 0.001 \\
\hline Bronchitis & $220(8.8)$ & $137(4.7)$ & $<0.001$ \\
\hline
\end{tabular}

${ }^{1}$, occupations not belonging to the below types or parents had multiple occupations are not shown in the chart. ${ }^{2}$, farmer and worker who works in a factory or in the production of chemicals, fertilizers, and paints. ${ }^{3}$, businessman, education or medical staff, civil servant, and military personnel. 


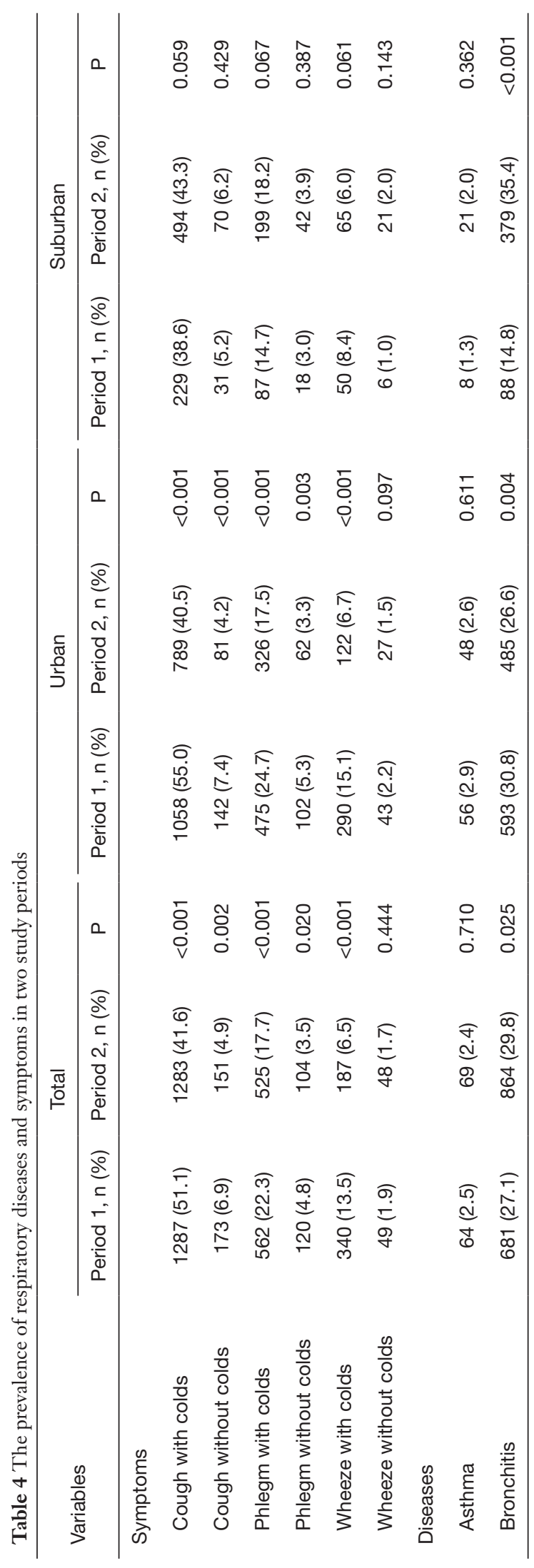

shown in Table 4. Overall, children's respiratory health has improved, particularly for the prevalence of wheeze with cold from period 1 to period 2 (13.5\% vs. 6.5\%). The improvement in respiratory health was more pronounced in urban children than in suburban children. Except for wheeze without colds and asthma, children's respiratory symptoms and diseases in urban area has decreased significantly, such as cough with colds (from $55.0 \%$ to $40.5 \%$ ), bronchitis (from $30.8 \%$ to $26.6 \%$ ). In the suburb area, however, there was no significant decrease in those symptoms or diseases. And we even observed a significant increase in the prevalence of bronchitis, from $14.8 \%$ in period 1 to $35.4 \%$ in period 2 (Table 4). Interestingly, the prevalence of respiratory symptoms and diseases in the suburban area was lower than that in urban area in period 1, while it turned to be opposite for most symptoms and diseases in period 2 (Table S1).

Figure 1 shows the association on the basis of ORs and 95\% CI between the coal use, EST, or kitchen smoke and children's respiratory health, after adjusting for area (urban vs. suburban), gender, age, parental occupation, parental education, breast-feeding, sleep in own room, sleep in own bed, parental asthma, parental bronchitis and other two focused home environmental risk factors. Coal use was significantly associated with phlegm when having colds $(\mathrm{OR}=1.26,95 \% \mathrm{CI}: 1.02-1.56)$ and asthma $(\mathrm{OR}=2.34$, 95\% CI: $1.30-4.23)$ in period 1 . There were significant associations of ETS exposure with cough (OR $=1.30,95 \%$ CI: $1.03-1.64)$ and phlegm (OR $=1.35,95 \%$ CI: $1.01-1.82$ ) when having colds in period 1 . Twenty-five years later, exposure to ETS was associated with cough without colds $(\mathrm{OR}=1.70,95 \%$ CI: 1.070-2.70) and bronchitis $(\mathrm{OR}=1.35$, 95\% CI: 1.09-1.68). There was no significant association between kitchen smoke exposure and respiratory disease and symptoms in period 1 . However, in period 2, children who exposed to kitchen smoke had increased risk of wheeze with colds (OR $=2.05,95 \%$ CI: $1.15-3.66)$ and wheeze without colds $(\mathrm{OR}=3.60,95 \% \mathrm{CI}: 1.22-10.65)$, while having a decrease risk for bronchitis (OR $=0.51,95 \%$ CI: 0.32-0.81).

\section{Discussion}

The two cross-sectional surveys on children's respiratory health, which were respectively conducted in 1993 to 1996 and 2017 to 2018 in Wuhan, found significant improvements in both household environmental conditions and children's respiratory health. The proportions of children exposure to ETS ( $86.6 \%$ to $45.9 \%$ ), coal use 

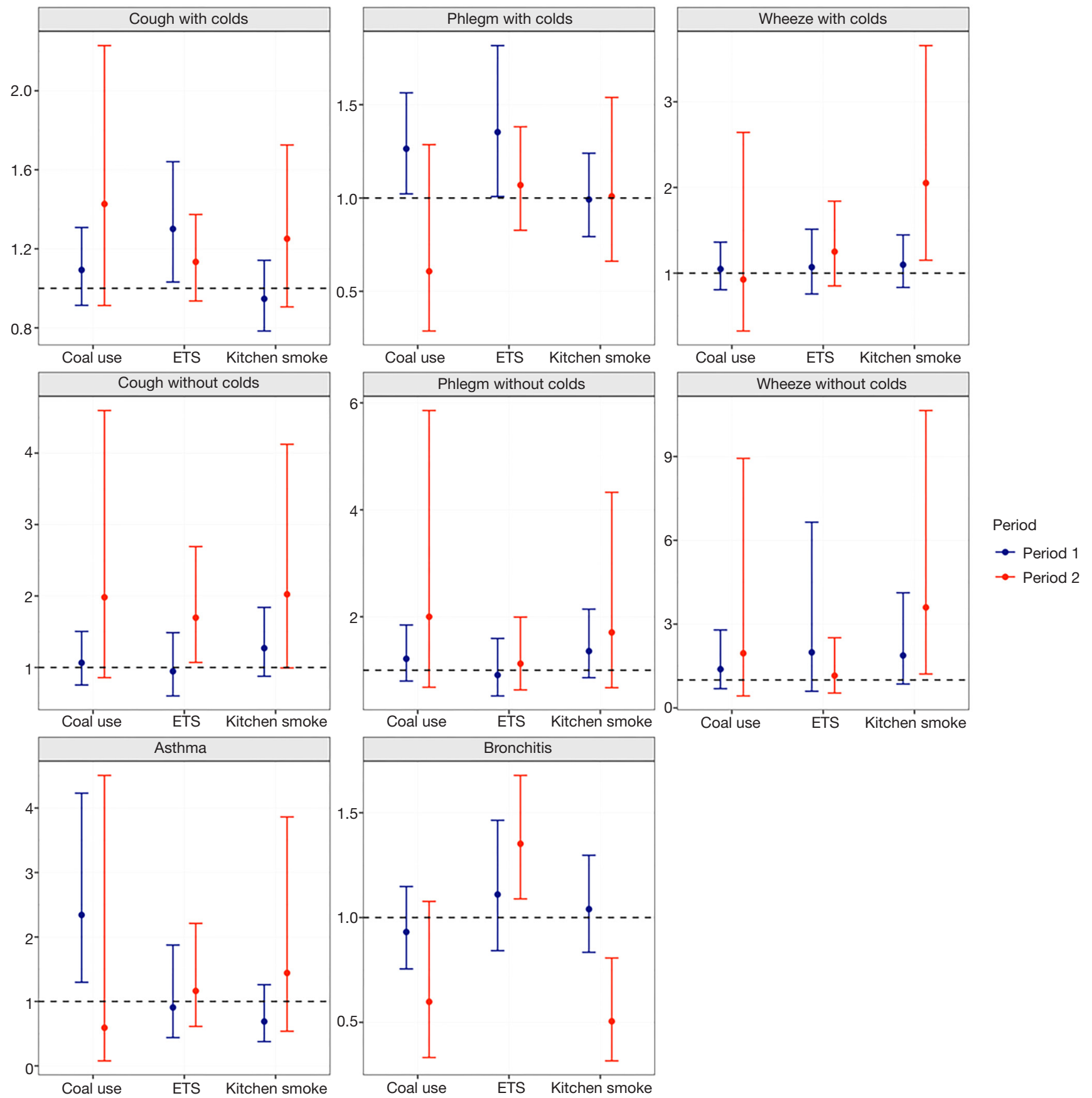

Figure 1 The association between respiratory symptoms and diseases and household environmental determinants, showing odds ratios (ORs) in reference to the absence of each determinant. ORs were adjusted for residential area, gender, age, parental occupation, parental education, breast-feeding, sleep in own room, sleep in own bed, parental asthma, parental bronchitis, and the two co-determinants.

( $47.6 \%$ to $4.9 \%)$ and kitchen smoke $(58.9 \%$ to $7.3 \%)$ have greatly decreased, which used to be a great concern in household environment. As a whole, there was also a significant decrease in the prevalence of respiratory symptoms and diseases in children. The association between those three risk factors and respiratory diseases and symptoms have also changed, after adjusting for the covariates of gender, age, residential area, breast-feeding, 
sleeping in own room, sleeping in own bed, parental occupation, parental education, parental asthma, parental bronchitis and the other two home environmental risk factors.

The improvements in children's respiratory health have been accompanied by the improvement in three household environmental risk factors pertinent to indoor air quality. Particularly, such improvements were more pronounced in the urban area. Some early studies have observed that children in urban areas have a higher prevalence of respiratory problems than children in suburban areas $(28,29)$, which is consistent with our findings from period 1 survey. However, recent studies have found some conflicting results. The occurrence of acute respiratory tract infection in a group of Indian children living is rural areas was higher as compared to those living in urban areas (30). In period 2, we also found higher prevalence of respiratory diseases and symptoms in the suburban (closer to rural) area than in the urban area. The discrepancies of that change could be mainly attributed to the difference in air pollution in rural areas in the past 25 years (31). Nowadays in China, ambient air pollution in suburb areas tends to be higher than that in urban area (32) because industrial facilities are typically located in suburban areas and the implementation of environmental protection policies tends to be less stringent in suburban areas (33). Additionally, differences in health awareness and environmental related behaviors between urban and rural areas over two periods also lead to differences in the prevalence of respiratory symptoms and diseases. The condition of medical care can affect the consciousness and treatment behavior of parents to children's respiratory health problems (34). Increased health awareness has led parents to pay more attention to their children's symptoms and seek medical diagnosis, resulting in fewer missed detection (35). The Chinese government has been expanding health insurance coverage and improving health service utilization. In comparison with period 1, urban-rural disparities in children's respiratory diseases and symptoms have been narrowed in period 2 . It could be attributed to those suburban parents may pay more attention to the health of children and tend to seek medical consultation resulting in observation of increasing prevalence after decades. However, we cannot conclude which one was more important to the disparities among environmental factors and medical awareness. Thus, it is necessary to determine whether this is caused by past prevalence reporting bias due to lack of medical awareness or by differences in living environment between urban and rural areas in the future.

Among the respiratory symptoms and diseases, bronchitis of children in Wuhan requires special attention. The prevalence of bronchitis remained high, at $29.8 \%$ in period 2. Similarly, in Chongqing, one of the four cities in the original and follow-up Four Chinese City Study, the prevalence of children's bronchitis in 2017 (23.6\%) was significantly higher than that in $1993(17.7 \%)(\mathrm{OR}=1.89$, 95\% CI: 1.54-2.31) (36). To date, few studies focused on the prevalence of bronchitis in children. Bronchitis is a serious disease and is associated with worse lung function, more dyspnea, and increased risk for developing asthma and chronic obstructive pulmonary disease in later life (37-39).

Although we have observed a decrease in ambient concentrations of air pollutants in Wuhan in recent decades, the annual mean of fine particulate matter $\left(\mathrm{PM}_{2.5}\right)$ in 2017 was still above $50 \mu \mathrm{g} / \mathrm{m}^{3}$, exceeding the World Health Organization (WHO) Air Quality Interim Target-1 (WHO 2005) of $35 \mu \mathrm{g} / \mathrm{m}^{3}(40,41)$. Outdoor air pollution alone cannot fully account for the health effects, especially when children stay indoors for a long time. In this study, we focus on three indoor air quality related household environmental determinants, namely coal use, EST, and kitchen smoke.

Indoor coal burning in Chinese homes is mainly used for cooking and heating (42). According to Chinese governmental policies, Wuhan is classified as a "heatingneedless" city where no heating infrastructure is planned in building designs. Our research also found that the vast majority of indoor coal burning in Wuhan is used for cooking rather than heating. We found that burning coal in period 1 was a risk factor for cough with colds and asthma whose associations reach statistical significance. Coal burning releases sulfur dioxide, carbon monoxide, particulate matter and other toxic and harmful pollutants $(43,44)$, which are harmful to respiratory health. However, we did not find significant respiratory health risks in children from burning coal in period 2. This may be attributed to the relatively low coal use rate $(4.9 \%)$ and improved coal quality in period 2. Other cities in this series of studies, such as Lanzhou and Chongqing, have also seen significant declines in indoor coal use. In period 2, coal burning was no longer a prominent problem affecting children's respiratory health in Lanzhou and Chongqing $(45,46)$.

The association between ETS and respiratory issues such as chronic bronchitis is well known $(47,48)$ and our finding in period 2 was consistent with this. Children are exposed to ETS mainly through living with smokers 
$(49,50)$. Studies have found that ETS exposure can cause cough, wheezing and asthma attacks in children (51-53). The proportion of mothers in Wuhan who smoked was very low. It is also possible for children to live with family members who smoke, but this situation rarely occurred and it is impractical to assess the total true ETS exposure in our study. Hence, smoking status of fathers is the best indicator for home ETS exposure in our study subjects. We observed a significant decline in paternal smoking rates, which may attribute to increased health awareness and smoking bans $(54,55)$. Both the reduction in amount of cigarettes and change in smoking site can affect children's actual exposure to ETS.

In this study, we investigated the ventilation in kitchen as a surrogate of indoor kitchen smoke exposure. Although its effects were not significant on most of the outcomes assessed in this study, kitchen smoke has been observed to have a negative effect on wheezing symptoms in children. Indoor mechanical ventilation has also been shown to modify the effects of indoor air pollutants on respiratory health $(56,57)$. However, kitchen may not be the main living area for elementary-school-age children. This may explain the null effects of kitchen ventilation (kitchen smoke exposure) in our children participants.

There are some limitations in this study. It is an inherent limitation of cross-sectional studies that two cross-sectional comparisons cannot accurately measure the influence of factors varying over time on the results. We hope to find out the corresponding exposure of children through questionnaires, although questionnaires cannot enable us to obtain the accurate exposure dose. Although we know coal use, ETS and kitchen smoke are important contributors to indoor air pollution, but we realize that indoor pollution sources are beyond those three factors. Emerging sources in Chinese households, such as decoration materials (58), indoor mildew (59), pet dander (60), were not considered in this comparison study. Since we considered the new pollution characteristics brought about by lifestyle changes or new concerns found in recent studies, we modified the questionnaire concerning these factors in period 2 including the proportion of the use of air purifiers and whether there was dampness. These can affect indoor air quality and further benefit to respiratory health (61-64). Unfortunately, the period 1 study did not collect data on these sources as they were nonexistent or not recognized, prohibiting us to consider these in our comparisons between the two periods, which was the main aim of the present study.

\section{Conclusions}

As a whole, children's respiratory health symptoms have improved after 25 years from earlier 1990s in Wuhan. However, in the stratified analysis we found that this improvement was mainly due to the improvement in children living in urban areas of the city. In contrast, no significant improvements were observed for the prevalence of asthma and that of bronchitis. Household risk factors pertinent to indoor air quality, including coal use, ETS, and kitchen smoke, were significantly improved. These improvements may have contributed to the improvements in some of the respiratory health outcomes.

\section{Acknowledgments}

We are particularly indebted to the children, their parents and the schools for their time and enthusiastic participation. We also appreciate all those who helped me during the implementation of the project.

Funding: This work was supported by the National Science Foundation (41977374) the National Key Research and Development Program of China (2016YFC1302501).

\section{Footnote}

Provenance and Peer Review: This article was commissioned by the Guest Editors (Junfeng Zhang, Howard Kipen and Haidong Kan) for the series "Children's Respiratory Health and Air Quality" published in Journal of Thoracic Disease. The article has undergone external peer review.

Reporting Checklist: The authors have completed the STROBE reporting checklist. Available at https://dx.doi. org/10.21037/jtd-20-2170

Data Sharing Statement: Available at https://dx.doi. org/10.21037/jtd-20-2170

Conflicts of Interest: All authors have completed the ICMJE uniform disclosure form (available at https:// dx.doi.org/10.21037/jtd-20-2170). The series “Children's Respiratory Health and Air Quality" was commissioned by the editorial office without any funding or sponsorship. JJZ served as the unpaid Guest Editor of the series. JG and JJZ serves as editorial board members of Fournal of Thoracic Disease. The authors have no other conflicts of interest to 
declare.

Ethical Statement: The authors are accountable for all aspects of the work in ensuring that questions related to the accuracy or integrity of any part of the work are appropriately investigated and resolved. The study was conducted in accordance with the Declaration of Helsinki (as revised in 2013). This study was approved by the Committee on Ethics of Biomedicine Research, Duke Kunshan University, Jiangsu (No. FWA00021580). Parents gave written consent for the participation of themselves and their children in the study.

Open Access Statement: This is an Open Access article distributed in accordance with the Creative Commons Attribution-NonCommercial-NoDerivs 4.0 International License (CC BY-NC-ND 4.0), which permits the noncommercial replication and distribution of the article with the strict proviso that no changes or edits are made and the original work is properly cited (including links to both the formal publication through the relevant DOI and the license). See: https://creativecommons.org/licenses/by-nc-nd/4.0/.

\section{References}

1. Williams BG, Gouws E, Boschi-Pinto C, et al. Estimates of world-wide distribution of child deaths from acute respiratory infections. Lancet Infect Dis 2002;2:25-32.

2. He C, Liu L, Chu Y, et al. National and subnational allcause and cause-specific child mortality in China, 19962015: a systematic analysis with implications for the Sustainable Development Goals. Lancet Glob Health 2017;5:e186-97.

3. Liu L, Oza S, Hogan D, et al. Global, regional, and national causes of child mortality in 2000-13, with projections to inform post-2015 priorities: an updated systematic analysis. Lancet 2015;385:430-40.

4. Shi P, Zhang X, Liu L, et al. Age- and gender-specific trends in respiratory outpatient visits and diagnoses at a tertiary pediatric hospital in China: a 10-year retrospective study. BMC Pediatr 2020;20:115.

5. Parker JD, Akinbami LJ, Woodruff TJ. Air pollution and childhood respiratory allergies in the United States. Environ Health Perspect 2009;117:140-7.

6. Blaiss M. Current concepts and therapeutic strategies for allergic rhinitis in school-age children. Clin Ther 2004;26:1876-89.

7. van Aalderen WM. Childhood asthma: diagnosis and treatment. Scientifica (Cairo) 2012;2012:674204.

8. Peel JL, Tolbert PE, Klein M, et al. Ambient air pollution and respiratory emergency department visits. Epidemiology 2005;16:164-74.

9. Atkinson RW, Anderson HR, Sunyer J, et al. Acute effects of particulate air pollution on respiratory admissions: results from APHEA 2 project. Air Pollution and Health: a European Approach. Am J Respir Crit Care Med 2001;164:1860-6.

10. Sundell J. On the history of indoor air quality and health. Indoor Air 2004;14 Suppl 7:51-8.

11. Wallace L. Indoor particles: a review. J Air Waste Manag Assoc 1996;46:98-126.

12. Zhao X, Duan X, Wang B. Environmental Exposure Related Activity Patterns Survey of Chinese Population (Children).

Beijing: China Environmental Science Press, 2016.

13. Valent F, Little D, Bertollini R, et al. Burden of disease attributable to selected environmental factors and injury among children and adolescents in Europe. Lancet 2004:363:2032-9.

14. Vanker A, Gie RP, Zar HJ. The association between environmental tobacco smoke exposure and childhood respiratory disease: a review. Expert Rev Respir Med 2017;11:661-73.

15. Smith KR. Indoor air pollution in developing countries: recommendations for research. Indoor Air 2002;12:198-207.

16. Svendsen K, Sjaastad AK, Sivertsen I. Respiratory symptoms in kitchen workers. Am J Ind Med 2003;43:436-9.

17. Willers SM, Brunekreef B, Oldenwening M, et al. Gas cooking, kitchen ventilation, and exposure to combustion products. Indoor Air 2006;16:65-73.

18. Bjerg A, Hedman L, Perzanowski MS, et al. Family history of asthma and atopy: in-depth analyses of the impact on asthma and wheeze in 7- to 8-year-old children. Pediatrics 2007;120:741-8.

19. Camilli AE, Holberg CJ, Wright AL, et al. Parental childhood respiratory illness and respiratory illness in their infants. Group Health Medical Associates. Pediatr Pulmonol 1993;16:275-80.

20. Choo CP, Jalaludin J. An overview of indoor air quality and its impact on respiratory health among Malaysian school-aged children. Rev Environ Health 2015;30:9-18.

21. Xu SC, Miao YM, Gao C, et al. Regional differences in impacts of economic growth and urbanization on air pollutants in China based on provincial panel estimation. J Clean Prod 2019;208:340-52.

22. Zhang JJ, Hu W, Wei F, et al. Children's respiratory morbidity prevalence in relation to air pollution in four 
Chinese cities. Environ Health Perspect 2002;110:961-7.

23. Wuhan Bureau of Statistics. Statistical Communique of Wuhan on the 2019 National Economic and Social Development. Available online: http://tjj.wuhan.gov.cn/ tjfw/tjgb/202004/t20200429_1191417.shtml

24. Wuhan Bureau of Statistics. Statistical Communique of Wuhan on the 2008 National Economic and Social Development. Available online: http://tjj.wuhan.gov.cn/ tjfw/tjgb/202001/t20200115_841055.shtml

25. Wuhan Bureau of Statistics. Statistical Communique of Wuhan on the 2018 National Economic and Social Development Available online: http://tjj.wuhan.gov.cn/ tjfw/tjgb/202001/t20200115_841065.shtml

26. The American review of respiratory disease. Epidemiology Standardization Project (American Thoracic Society). Am Rev Respir Dis 1978;118:1-120.

27. GBD 2015 Risk Factors Collaborators. Global, regional, and national comparative risk assessment of 79 behavioural, environmental and occupational, and metabolic risks or clusters of risks, 1990-2015: a systematic analysis for the Global Burden of Disease Study 2015. Lancet 2016;388:1659-724.

28. Wieringa MH, Weyler JJ, Van Bastelaer FJ, et al. Higher asthma occurrence in an urban than a suburban area: role of house dust mite skin allergy. Eur Respir J 1997;10:1460-6.

29. Wieringa MH, Weyler JJ, Nelen VJ, et al. Prevalence of respiratory symptoms: marked differences within a small geographical area. Int J Epidemiol 1998;27:630-5.

30. Prajapati B, Talsania NJ, Lala MK, et al. Epidemiological profile of acute respiratory infections (ARI) in under five age group of children in urban and rural communities of Ahmedabad district, Gujarat. Int J Med Sci Public Health 2012;1:52.

31. Liu P, Wang X, Fan J, et al. Effects of Air Pollution on Hospital Emergency Room Visits for Respiratory Diseases: Urban-Suburban Differences in Eastern China. Int J Environ Res Public Health 2016;13:341.

32. Huang D, Li Q, Wang X, et al. Characteristics and Trends of Ambient Ozone and Nitrogen Oxides at Urban, Suburban, and Rural Sites from 2011 to 2017 in Shenzhen, China. Sustainability 2018;10. doi: 10.3390/su10124530

33. Lin C, Lau AKH, Li Y, et al. Difference in PM2.5 Variations between Urban and Rural Areas over Eastern China from 2001 to 2015. Atmosphere 2018;9. doi: 10.3390/atmos9080312

34. Majumdar A, Premarajan KC, Ganesh KS, et al. Rural urban differentials of treatment seeking behaviour for acute respiratory infection among children in Puducherry.
Natl J Community Med 2014;5:325-8.

35. Lamberti LM, Fischer Walker CL, Taneja S, et al. The Influence of Episode Severity on Caregiver Recall, Careseeking, and Treatment of Diarrhea Among Children 2-59 Months of Age in Bihar, Gujarat, and Uttar Pradesh, India. Am J Trop Med Hyg 2015;93:250-6.

36. Li Y, Huang X, Liu Q, et al. Changes in children's respiratory morbidity and residential exposure factors over 25 years in Chongqing, China. J Thorac Dis 2020;12:6356-64.

37. Mejza F, Gnatiuc L, Buist AS, et al. Prevalence and burden of chronic bronchitis symptoms: results from the BOLD study. Eur Respir J 2017;50:1700621.

38. Fuhrman C, Roche N, Vergnenegre A, et al. Chronic bronchitis: prevalence and quality of life. Analysis of data from the French Health Interview Survey 2002-2003. Rev Mal Respir 2009;26:759-68.

39. Beridze V, Abuladze L, Partenadze N, et al. Childhood asthma in Batumi, Georgia: Prevalence and environmental correlates. J Asthma 2018;55:43-9.

40. Liu D, Deng Q, Zhou Z, et al. Variation Trends of Fine Particulate Matter Concentration in Wuhan City from 2013 to 2017. Int J Environ Res Public Health 2018;15:1487

41. Yao L, Lu N. Spatiotemporal distribution and short-term trends of particulate matter concentration over China, 2006-2010. Environ Sci Pollut Res Int 2014;21:9665-75.

42. Florig HK. China's air pollution risks. Environ Sci Technol 1997;31:274A-9A.

43. Finkelman RB, Belkin HE, Zheng B. Health impacts of domestic coal use in China. Proc Natl Acad Sci U S A 1999;96:3427-31.

44. Zhang J, Smith KR. Emissions of carbonyl compounds from various cookstoves in China. Environ Sci Technol 1999;33:2311-20.

45. Cao S, Wen D, Li S, et al. Changes in children's asthma prevalence over two decades in Lanzhou: effects of socioeconomic, parental and household factors. J Thorac Dis 2020;12:6365-78.

46. Li W, Liu Q, Chen Y, et al. Effects of indoor environment and lifestyle on respiratory health of children in Chongqing, China. J Thorac Dis 2020;12:6327-41.

47. Rylander E, Pershagen G, Eriksson M, et al. Parental smoking and other risk factors for wheezing bronchitis in children. Eur J Epidemiol 1993;9:517-26.

48. LeVan TD, Koh WP, Lee HP, et al. Vapor, dust, and smoke exposure in relation to adult-onset asthma and chronic respiratory symptoms: the Singapore Chinese 
Health Study. Am J Epidemiol 2006;163:1118-28.

49. Jaakkola JJ, Jaakkola MS. Effects of environmental tobacco smoke on the respiratory health of children. Scand J Work Environ Health 2002;28 Suppl 2:71-83.

50. Salo PM, Xia J, Johnson CA, et al. Respiratory symptoms in relation to residential coal burning and environmental tobacco smoke among early adolescents in Wuhan, China: a cross-sectional study. Environ Health 2004;3:14.

51. Mannino DM, Moorman JE, Kingsley B, et al. Health effects related to environmental tobacco smoke exposure in children in the United States: data from the Third National Health and Nutrition Examination Survey. Arch Pediatr Adolesc Med 2001;155:36-41.

52. Cook DG, Strachan DP. Health effects of passive smoking-10: Summary of effects of parental smoking on the respiratory health of children and implications for research. Thorax 1999;54:357-66.

53. Berman BA, Wong GC, Bastani R, et al. Household smoking behavior and ETS exposure among children with asthma in low-income, minority households. Addict Behav 2003;28:111-28.

54. Aresh Azizi A. Is this the end of the beginning for smoking in China? Challenges, context and change. Glob Health Promot 2017;24:79-83.

55. Lu P, Ye C, Sun Q. Change in smoking behaviour and its influencing factors among residents in five provinces of China. China Journal of Public Health 2019;35:963-8.

56. Rim D, Wallace L, Nabinger S, et al. Reduction of exposure to ultrafine particles by kitchen exhaust hoods: The effects of exhaust flow rates, particle size, and burner

Cite this article as: Meng X, Cao S, Li S, Yan M, Guo Q, Gong J, Liu Q, Zhang JJ, Duan X. Household environmental factors and children's respiratory health: comparison of two cross-sectional studies over 25 years in Wuhan, China. J Thorac Dis 2021;13(7):4589-4600. doi: 10.21037/jtd-20-2170 position. Sci Total Environ 2012;432:350-6.

57. Daisey JM, Angell WJ, Apte MG. Indoor air quality, ventilation and health symptoms in schools: an analysis of existing information. Indoor Air 2003;13:53-64.

58. Ma G, Li G, editors. Indoor Air Pollution Caused by Interior Architecture Decoration and Reason of not Absolutely Forbidden. 4th International Conference on Bioinformatics and Biomedical Engineering, 2010.

59. Brunekreef B. Damp housing and adult respiratory symptoms. 1992. Available online: https://onlinelibrary. wiley.com/doi/abs/10.1111/j.1398-9995.1992.tb00672.x

60. Yarnell JW, Stevenson MR, MacMahon J, et al. Smoking, atopy and certain furry pets are major determinants of respiratory symptoms in children: the International Study of Asthma and Allergies in Childhood Study (Ireland). Clin Exp Allergy 2003;33:96-100.

61. Sahakian N, Park JH, Cox-Ganser J. Respiratory morbidity and medical visits associated with dampness and air-conditioning in offices and homes. Indoor Air 2009;19:58-67.

62. Shao D, Du Y, Liu S, et al. Cardiorespiratory responses of air filtration: A randomized crossover intervention trial in seniors living in Beijing: Beijing Indoor Air Purifier StudY, BIAPSY. Sci Total Environ 2017;603-604:541-9.

63. Brunekreef B, Dockery DW, Speizer FE, et al. Home dampness and respiratory morbidity in children. Am Rev Respir Dis 1989;140:1363-7.

64. Paulin LM, Diette GB, Scott M, et al. Home interventions are effective at decreasing indoor nitrogen dioxide concentrations. Indoor Air 2014;24:416-24. 
Supplementary

Table S1 The prevalence of respiratory diseases and symptoms between urban and suburban subjects

\begin{tabular}{|c|c|c|c|c|c|c|}
\hline Variables & \multicolumn{3}{|c|}{ Period 1} & \multicolumn{3}{|c|}{ Period 2} \\
\hline \multicolumn{7}{|l|}{ Symptoms } \\
\hline Cough with colds & 1,058 (55.0) & 229 (38.6) & $<0.001$ & 789 (40.5) & $494(43.3)$ & 0.124 \\
\hline Cough without colds & $142(7.4)$ & $31(5.2)$ & 0.070 & $81(4.2)$ & $70(6.2)$ & 0.013 \\
\hline Phlegm without colds & $102(5.3)$ & $18(3.0)$ & 0.024 & $62(3.3)$ & $42(3.9)$ & 0.448 \\
\hline Wheeze with colds & $290(15.1)$ & $50(8.4)$ & $<0.001$ & $122(6.7)$ & $65(6.0)$ & 0.437 \\
\hline Wheeze without colds & $43(2.2)$ & $6(1.0)$ & 0.059 & $27(1.5)$ & $21(2.0)$ & 0.350 \\
\hline \multicolumn{7}{|l|}{ Diseases } \\
\hline
\end{tabular}

